\title{
Review finds that severe periodontitis affects $11 \%$ of the world population
}

\section{Abstracted from}

\section{Kassebaum NJ, Bernabé E, Dahiya M, Bhandari B, Murray CJ, Marcenes W.}

Global Burden of Severe Periodontitis in 1990-2010: A Systematic Review and Meta-regression.

J Dent Res 2014; pii: 0022034514552491. [Epub ahead of print] Review. PubMed PMID: 25261053.

Address for correspondence: Dr. W. Marcenes, Institute of Dentistry,

Barts and The London School of Medicine and Dentistry, Queen Mary University of London,

London, UK. E-mail:w.marcenes@qmul.ac.uk

\section{Question: What is the global prevalence and incidence of severe periodontitis (SP)?}

Data sources Medline, Embase and LILACS. Chief Dental Officers worldwide were contacted to request conference reports, theses, government reports and unpublished survey data.

Study selection Selection was carried out independently by two reviewers. Longitudinal or crossover studies based on random samples representing national, subnational or community populations with SP defined as; a community periodontal index of treatment needs (CPITN) score of four, a clinical attachment loss (AL) more than $6 \mathrm{~mm}$, or a gingival PD more than $5 \mathrm{~mm}$.

Data extraction and synthesis Data extraction and synthesis followed Global Burden of Disease (GBD) 2010 standards and modeled using a Bayesian meta-regression tool developed for the GBD 2010. Countries were grouped in 21 regions and seven super-regions by geographical proximity and mean age of death.

Results Seventy two studies involving 291,170 patients were included. The majority of these (65) were prevalence studies. In 2010 , SP was the sixth-most prevalent condition, affecting $10.8 \%$ (95\% uncertainty interval [UI]: 10.1\%-11.6\%) or 743 million people worldwide. Between 1990 and 2010 the global age-standardised prevalence of SP in the entire population was static at $11.2 \%$ (95\% Ul: $10.4 \%-11.9 \%$ in 1990 and $10.5 \%-12.0 \%$ in 2010 ) a non-significant increase from the 1990 incidence of SP. The age-standardised incidence of SP in 2010 was 701 cases per 100,000 person-years (95\% uncertainty interval: 599-823), a non-significant increase from the 1990 incidence of SP. Prevalence increased gradually with age, showing a steep increase between the third and fourth decades of life that was driven by a peak in incidence at around 38 years of age. Conclusions Policy makers need to be aware of a predictable increasing burden of SP due to the growing world population associated with an increasing life expectancy and a massive decrease in the prevalence of tooth loss throughout the world from 1990 to 2010. These changes underscore the enormous public health challenge posed by SP and are a microcosm of the epidemiologic transition to non-communicable diseases occurring in many countries.

\section{Commentary}

This review of observational data used a good search strategy and a meta-regression tool developed for the GBD 2010 study. They also imposed some disease specific limits to reflect the known

\begin{tabular}{|c|c|c|c|}
\hline Location & & $\begin{array}{l}\text { Prevalence } \\
\text { per } 100 \\
\text { population }\end{array}$ & $\begin{array}{l}95 \% \\
\text { uncertainty } \\
\text { intervals }\end{array}$ \\
\hline Global & & 11.2 & $(10.5-12.0)$ \\
\hline $\begin{array}{l}\text { Asia Pacific, } \\
\text { high income }\end{array}$ & & 8.0 & $(6.6-10.4)$ \\
\hline \multicolumn{4}{|l|}{ Asia } \\
\hline & Central & 13.8 & $(10.0-19.3)$ \\
\hline & East & 10.4 & $(8.8-12.2)$ \\
\hline & South & 10.2 & $(9.1-11.8)$ \\
\hline & Southeast & 13.1 & $(11.3-15.1)$ \\
\hline Australasia & & 14.9 & $(13.3-16.5)$ \\
\hline Caribbean & & 8.6 & $(5.7-12.5)$ \\
\hline \multicolumn{4}{|l|}{ Europe } \\
\hline & Central & 12.1 & $(8.8-16.7)$ \\
\hline & Eastern & 14.0 & $(8.0-24.0)$ \\
\hline & Western & 9.4 & $(8.6-10.3)$ \\
\hline \multicolumn{4}{|l|}{ Latin America } \\
\hline & Andean & 15.2 & $(9.2-22.7)$ \\
\hline & Central & 15.1 & $(9.6-22.4)$ \\
\hline & Southern & 20.4 & $(12.3-31.4)$ \\
\hline & Tropical & 18.5 & $(17.5-19.6)$ \\
\hline $\begin{array}{l}\text { North Africa/ } \\
\text { Middle East }\end{array}$ & & 10.4 & $(8.4-13.0)$ \\
\hline $\begin{array}{l}\text { North America, } \\
\text { high income }\end{array}$ & & 7.2 & $(6.4-8.1)$ \\
\hline Oceania & & 4.2 & $(2.4-7.2)$ \\
\hline \multicolumn{4}{|l|}{ Sub-Saharan Africa } \\
\hline & Central & 13.3 & $(7.7-21.5)$ \\
\hline & East & 20.1 & $(16.1-25.0)$ \\
\hline & Southern & 9.2 & $(5.0-15.4)$ \\
\hline & West & 9.3 & $(6.6-14.0)$ \\
\hline
\end{tabular}


epidemiology of SP and made other adjustments to fit the observed natural history of SP. Additional adjustments were made to account for the systematic bias that would result from only assessing dentate people.

The 72 studies included data from 37 countries providing data from 16 of the 21 regions and all seven of the super-regions. As the majority were prevalence studies a summary of the calculated prevalence data for 2010 from the study is shown in Table1. This demonstrates geographical differences between the regions ranging from $4.2 \%-20.4 \%$.

Only two incidence studies could be included in the review and using these studies together with indirect data from the other included studies, incidence of 701 cases per 100,000 person-years (95\% uncertainty interval: 599-823) with a peak incidence at about 38 years of age was calculated.

While this review pulls together the best available observational evidence and has applied a good methodological approach to data gathering and analysis there still remain challenges in defining and identifying periodontal disease. A systematic review by Savage et al. ${ }^{1}$ concluded that epidemiological studies of periodontal diseases are complicated by the diversity of definitions and measurements used to describe and quantify them, and there is a lack of consensus on a uniform definition and classification of periodontal disease. For example Savage at al. noted that in 15 studies the threshold for a diagnosis of periodontitis when $\mathrm{AL}$ was the criterion ranged from 2 to $\geq 6 \mathrm{~mm}$ and when PPD was used, from 3 to $\geq 6 \mathrm{~mm}$. In this current review this variation has been mitigated by employing a clear case definition however, as with some of the other decisions taken by the reviewers in this publication not all will agree.

While this review does highlight the ongoing public health challenge of severe periodontal disease the broader challenge of the wider family of periodontal diseases is also a significant challenge, as the 2009 Adult Dental Health survey in the UK ${ }^{2}$ showed, only $17 \%$ of adults had healthy gums, $66 \%$ had visible plaque and $65 \%$ bleeding gums.

\section{Derek Richards}

Centre for Evidence-based Dentistry, Dental Health Services Research Unit, Dundee Dental Hospital and School, University of Dundee, Scotland

1. Savage A, Eaton KA, Moles DR, Needleman I. A systematic review of definitions of periodontitis and methods that have been used to identify this disease. J Clin Periodontol 2009; 36: 458-467.

2. The Health and Social Care Information Centre. The Adult Dental Health Survey 2009. Available from http://www.hscic.gov.uk/catalogue/PUB01086

Evidence-Based Dentistry (2014) 15, 70-71. doi:10.1038/sj.ebd.6401037 